\section{ENSINO DO DIREITO: O CONCEITO DE EDUCAÇÃo COM FUNDAMENTO NO ARTIGO 205 DA CONSTITUIÇÃo FEdERAL}

\section{Márcia Cristina de Souza Alvim}

\section{Sumário}

Introdução. O artigo 205 e a questão da dignidade da pessoa humana. A responsabilidade do educador. Três pilares da educação. Teoria e prática entrelaçadas. Pesquisa: ferramenta fundamental. Cidadania e uma nova palavra: felicidania. Conclusão. Referências.

\section{Resumo}

Exame da atuação do profissional do Direito voltado para o ensino. Constituição Federal e direito à educação: artigo 205. Objetivo do texto constitucional: promover pleno desenvolvimento de acordo com o Princípio da Dignidade da Pessoa. Conceitos do Princípio: Plácido e Silva; Jesús González Pérez. Dignidade pessoal: pré-requisito da plena cidadania. Desafio do educador semelhante ao do advogado: tarefas cada vez mais complexas. Carreira jurídica abre múltiplos campos de interesse e atuação. Habilidades fundamentais a serem desenvolvidas pelo aprendiz: cognitiva, social, emocional. Incentivar estudantes à reflexão e à relação entre os conteúdos adquiridos. Entrelaçar prática e teoria. Dominar mais de um campo de conhecimento. Pesquisa: necessidade essencial. Conjunção da cidadania com a felicidade: Terezinha Rios e sua felicidadania na ação docente.

\section{Palavras-chave}

Ensino jurídico. Direito à educação. Cidadania.

\section{Abstract}

Examination of the performance of the Law professional in Teaching. Federal Constitution and the Right to Education: article 205. Objective of the constitutional text: to promote full development in accordance with the Principle of the Dignity of a Human being. Concepts of the Principle: Plácido and Silva; Jesús González. Pérez: Personal dignity: prerequisite of full citizenship. Challenge of the educator similar to the challenge of a lanyer: more complex tasks each time. Legal career opens multiples fields of interest and development. Basic abilities to be developed by the apprentice: cognitive, social, emotional. To stimulate students to reflect and to see the relation between the acquired content. To interlace theory and practice. To dominate more than a field of knowledge. Essential Research: necessity. Conjunction of citizenship with happiness: Terezinha Rios and its "bappycitizenship" in the teaching process.

\section{Key Words}

Law teaching. Right to education. Citizenship.

OSASCO, ANO 5, N.5, 2005, P. 61-69
61 
Diante da necessidade permanente de atualização que é uma demanda do nosso tempo, e que também afeta, como não poderia deixar de ser, o ensino jurídico, e neste momento em que o tema da reforma do ensino superior vem sendo objeto de discussão entre os que trabalham na área, bem como nos meios de comunicação, e entre todos que se preocupam com a questão, revelando interesse no desenvolvimento harmonioso desse aspecto específico da nossa sociedade, gostaríamos de também fazer nossa contribuição, discutindo o tema do profissional do Direito voltado para a atividade da Educação, da formação dos jovens que se iniciam ou avançam em seus estudos nesta nossa área do conhecimento.

\section{O Artigo 205 e a questão da dignidade da pessoa humana}

Como ponto de partida, queremos utilizar um trecho da nossa Constituição Federal, especificamente do artigo 205, que trata do direito à educação.

Artigo 205 - A educação, direito de todos e dever do Estado e da família, será promovida e incentivada com a colaboração da sociedade, visando ao pleno desenvolvimento da pessoa, seu preparo para o exercício da cidadania e sua qualificação para o trabalho.

A educação, na visão constitucional, deve ser entendida dentro de uma visão ampliada. Por isso vai além da proteção a seus aspectos mais formais, quais sejam, a aquisição das ferramentas mínimas do desenvolvimento intelectual e da qualificação para o trabalho. Seu objetivo maior, que acaba contemplando todos os outros, é aquele que atende ao pleno desenvolvimento da pessoa, concretizando assim aquilo que é invocado no Princípio da Dignidade da Pessoa Humana, o nosso chamado supra princípio — que está no artigo $1^{\circ}$., inciso III, da Constituição Federal, e constitui a base do preparo para o exercício da cidadania.

Como ponto de partida para o conceito de dignidade podemos nos servir da definição formulada pelo professor Plácido e Silva:

derivado do latim dignitas (virtude, honra, consideração), em regra se entende a qualidade moral, que, possuída por uma pessoa, serve ao próprio respeito em que é tida. Compreende-se também como o próprio procedimento da pessoa, pelo qual se faz merecedora do conceito público. Mas, em sentido jurídico, também se entende como a distinção ou honraria conferida a uma pessoa, consistente em cargo ou título de alta graduação. ${ }^{1}$

\footnotetext{
${ }^{1}$ De PLÁCIDO E SILVA. Vocabulário jurídico, p. 526. 
Vejamos ainda, sobre esta questão, o que nos diz o pensador espanhol Jesús González Pérez:

La persona humana, su dignidad y los derechos a ella inherentes constituyen temas centrales de la Ciência y de la Filosofía del Derecho. Pero su interés sobrepasa los marcos puramente científicos para integrarse en el área de la problemática específicamente humana ${ }^{2}$. (...) El hombre destaca de toda la naturaleza, aparece como un ser superior al universo material. Dotado de inteligencia y libertad, está más allá de la Naturaleza y de la Historia. La libertad pertenece a la esencia del hombre 3 . (...) La dignidad de la persona es, pues, el rango de la persona como tal. ${ }^{4}(. .$.$) no admite discriminación alguna por razón de$ nacimiento, raza o sexo; opiniones o creencias. Es independiente de la edad, inteligencia y salud mental; de la situación en que se encuentre y de las cualidades, así como de la conducta y comportamiento. Por muy bajo que caiga el hombre, por grande que sea la degradación, seguirá siendo persona con la dignidad que ello comporta. (...) La dignidad de la persona no es superioridad de un hombre sobre otro, sino de todo hombre sobre los seres que carecen de razón." ${ }^{5}$

Tendo em vista todos estes motivos que, como diz o professor González Pérez, já entram no campo mais amplo das especificidades humanas, não será demais reiterar que a necessidade do incentivo ao desenvolvimento das potencialidades e da dignidade de cada um é uma espécie de pré-requisito sem o qual jamais será atingida a plenitude no exercício da dignidade social, ou seja, a condição de completa cidadania.

\section{A responsabilidade do educador}

Vejamos, antes de examinarmos a questão discutida neste item, como o professor Nicola Abbagnano define educação:

(...) a transmissão e o aprendizado das técnicas culturais que são as técnicas de uso, produção e comportamento, mediante as quais um grupo de homens é capaz de satisfazer suas necessidades (...). (...) o conjunto dessas técnicas se chama cultura, uma sociedade não pode sobreviver se sua cultura não é transmitida de geração para geração; as modalidades ou formas de realizar ou garantir essa transmissão chamam-se educação (...). ${ }^{6}$

\footnotetext{
${ }^{2}$ PÉREZ, Jesús González. La dignidad de la persona, p. 19.

${ }^{3}$ Idem, p. 23.

${ }^{4}$ Idem, p. 25.

${ }^{5}$ Idem, p. 26.

${ }^{6}$ ABBAGNANO, Nicola. Dicionário de filosofia, p. 305.
} 
Em virtude de tais razões e necessidades é que acreditamos que ser professora ou professor, em nossa área, e não só nela, implica um certo compromisso no desenvolvimento dessa visão do complexo papel a ser desempenhado por um verdadeiro educador, e que isso constitui um verdadeiro desafio, repleto de dificuldades, mas que devemos enfrentar integralmente, e cumprir da melhor forma que nos for possível.

Ser advogado também é um incessante desafio, como sabem os que já enfrentam os processos, os prazos, os embates que encaramos todos os dias. A nossa consciência profissional pede que sempre abracemos as causas de que somos incumbidos como sendo as únicas, as que estão em primeiro lugar, as que exigem toda nossa atenção.

A carreira jurídica, para a qual somos chamados a preparar tantos jovens, é uma das mais belas, pois abre um leque imenso de possibilidades profissionais nas mais diferentes áreas das atividades humanas. $\mathrm{O}$ interesse que se exige do advogado não tem limites, ele deve estar capacitado para rapidamente se ambientar e em seguida se aprofundar nas mais diversas áreas do conhecimento, em acordo com as variadas necessidades de seus clientes.

É por isso que aliar a profissão de advogado com a de professor, desde que imbuído do pleno espírito de sua missão educacional, acaba sendo um dos mais instigantes desafios que a área possibilita. Um desafio que deve ser equacionado e vencido, pois o que ele põe em jogo é a formação das futuras gerações de advogados, processo que vem enfrentando problemas e não pode, de maneira alguma, ser descurada, ser minimizada, ser considerada sem importância.

\section{Três pilares da educação}

O ensino superior, como sabemos, preocupa-se em qualificar para o trabalho, em levar aos estudantes os ensinamentos técnicos da Ciência do Direito. Mas é importante que se preocupe também em desenvolver o que, em Educação, chamamos babilidades fundamentais.

Vejamos quais são, segundo o professor Gabriel Chalita, essas habilidades fundamentais, aquilo que ele chama os três pilares da Educação:

Primeiro: Habilidade Cognitiva: "é a habilidade de absorver o conhecimento e de trabalhá-lo de forma eficiente e significativa" , relacionando-o criativamente com o repertório anterior do aprendiz. Falar em habilidade cognitiva significa falar em seleção de conteúdos. O "aprender a aprender" não envelhece nunca, o que envelhece é o

\footnotetext{
${ }^{7}$ CHALITA, Gabriel. A educação está no afeto, p. 193.

${ }^{8}$ Idem.

Revista MEstrado em Direito

OSASCO, ANO 5, N.5, 2005, P. 61-69
} 
conhecimento e não a habilidade. Esse método, essa ferramenta, uma vez adquiridos, nunca mais serão descartados.

Segundo: Habilidade Social: a vida em sociedade é necessária e essencial. O ser humano não consegue se desenvolver sem o outro; é preciso enfrentar a diversidade. Os relacionamentos ocorrem em vários níveis: relacionamentos familiares, escolares, profissionais, afetivos, políticos, ou seja, em todos os momentos da nossa vida estamos nos relacionando. A habilidade social é a preparação para o trabalho em grupo, em equipe, cuja aprendizagem pode ser significativa. $\mathrm{Na}$ habilidade social podemos destacar a solidariedade. E solidariedade é troca. É doação e recompensa; é entrega; é participação na história do outro; é uma permissão para que o outro participe da minha, da sua história.

Terceiro: Habilidade Emocional: O grande pilar da educação é a habilidade emocional. Trabalhar emoção requer paciência. "A emoção trabalha com a libertação da pessoa humana. A emoção é a busca pelo foco interior e exterior, de uma relação do ser humano com ele mesmo e com o outro" "É o caminho para construção da autonomia e da conseqüente felicidade.

Queremos reforçar e reafirmar uma idéia que nos parece muito importante: para alcançarmos o progresso dessas habilidades fundamentais na atividade do conhecimento, precisamos ter em mente que a educação precisa ser significativa, precisa ser de fato uma aquisição de conteúdo e, mais que isso, uma aquisição da capacidade de pensar e relacionar esses conteúdos adquiridos. Os estudantes de Direito não podem e nem devem decorar artigos de lei, memorizar ou mesmo estudar institutos jurídicos sem saber distinguir sua utilidade e possível serventia. Cada vez mais, reiteramos, dentro deste mundo globalizado, precisamos saber trabalhar com a informação, precisamos saber o porquê daquilo que estudamos, o porquê de determinados temas, o porquê da importância desses temas, de que forma serão úteis para o nosso desenvolvimento e que aplicabilidade terão nas nossas atividades cotidianas.

\section{Teoria e prática entrelaçadas}

Isso tudo faz ficar evidente a importância do professor/educador desenvolver, em suas aulas, questões práticas que estejam atreladas aos ensinamentos teóricos trazidos,

${ }^{9}$ CHALITA, Gabriel. A educação está no afeto, p. 213. 
que os possam exemplificar e clarificar. E nada melhor para o advogado, que tem os seus casos, que trabalha, que vivencia a profissão, do que levar esses casos para a sala de aula. Eles serão pretextos para discussões e debates, e servirão ainda para que os alunos experimentem, com essa atividade prática, a importância de conhecer toda a teoria que eles futuramente necessitarão aplicar em suas atividades profissionais.

Sabemos que essa tarefa não será fácil, será trabalhosa, contrária a qualquer espécie de acomodação, mas aí está o grande desafio para os professores. O sociólogo e pensador francês Edgar Morin, em sua obra $A$ cabeça bem feita, demonstra a importância de tornar o aprendizado significativo. O professor Edgar Morin nos faz lembrar um aforismo de Montaigne: "mais vale uma cabeça bem feita, do que bem cheia"10. Ou seja, mais vale uma cabeça que sabe pensar, que sabe trabalhar com a informação, do que uma cabeça que só recebe informações, que serve como depósito, e não sabe como utilizar e relacionar as informações recebidas.

Montaigne, aliás, deve ser lembrado como exemplo de interesse enciclopédico e capacidade de relacionar as mais diversas matérias. A leitura de seus Ensaios, um clássico da Filosofia deliciosamente eclético, deveria ser incentivada pelos educadores que trabalham na área do Direito. Só como um pequeno exemplo, vejamos o que ele diz sobre a complexidade da tarefa do educador:

Assim os homens: pouco custa semeá-los, mas depois de nascidos, educá-los e instruí-los é tarefa complexa, trabalhosa e temível. O que se revela de suas tendências é tão tênue e obscuro nos primeiros anos, e as promessas tão incertas e enganadoras que se faz difícil assentar um juízo seguro. ${ }^{11}$

E, lembrando-nos do exemplo do filósofo francês, gostaríamos de acrescentar a idéia da indispensável necessidade de adquirirmos conhecimentos específicos e especializados, que sejamos excelentes em determinado assunto, ou até mesmo em mais de um, mas sem nunca esquecer que seremos ainda melhores se adquirirmos e desenvolvermos um repertório geral, global, em relação ao conhecimento. Seremos bons profissionais se tivermos o domínio do conhecimento na nossa área jurídica específica, mas seremos excelentes se esses assuntos estiverem entrelaçados com um repertório de outras ciências e formas de pensamento, diferenciadas visões de mundo, como por exemplo, a sociologia, a psicologia, bem como a forma de pensar das principais religiões.

Essas matérias básicas, que nos são oferecidas no primeiro ano da faculdade de Direito, e para as quais desconhecemos, na maioria dos casos, naquele momento, qualquer

\footnotetext{
${ }^{10}$ MORIN, Edgar. A cabeça bem feita, p. 21.

${ }^{11}$ MONTAIGNE, Michel de. Da educação das crianças. Ensaios, p. 79. 
emprego, qualquer possibilidade de uso na vida profissional. É um estágio que deve ser rapidamente abandonado, uma consciência que o professor/educador deve, tão depressa quanto possa, ajudar o estudante a adquirir.

\section{Pesquisa: ferramenta fundamental}

Outro aspecto importante e que também está entre as necessidades contemporâneas que o educador deve incentivar e apoiar: o incremento da pesquisa científica dentro das faculdades e universidades. É fundamental convencer os alunos dessa necessidade do trabalho de pesquisa, mais que isso, é preciso fazê-los adquirir gosto, descobrir o prazer desse trabalho. A pesquisa traz embutida em si o processo criativo, a possibilidade de novas descobertas, contribuições inéditas para a Ciência Jurídica. O professor Pedro Demo, sociólogo, escreveu, em sua obra Pesquisa e construção do conhecimento, que "O questionamento" precisa ser "sistemático, crítico e criativo" 12 acrescentado da “intervenção prática inovadora"13. O referido professor dá ênfase à necessidade do desenvolvimento teórico, mas não esquece que também precisamos nos concentrar no enfrentamento e na resolução das questões práticas. Dar aos estudantes a capacidade de transitar intelectualmente por essas questões é uma das formas de cumprir o papel de oferecer uma verdadeira educação significativa.

E é exatamente nos exemplos, nos casos práticos, nas experiências pragmáticas do trabalho com os clientes, que melhor se pode demonstrar a importância de conhecer determinados temas teóricos. Só assim os estudantes poderão, por si mesmos, valorizar a aquisição daqueles assuntos que lhes pareceram, a princípio, não ter nenhuma relação com a carreira que haviam escolhido seguir. E essa forma de aprendizagem é valioso instrumento para efetiva aquisição de um ensino qualificado, voltado direta e preferencialmente para o que vai ser exigido na prática profissional.

\section{Cidadania e uma nova palavra: felicidania}

Outro dos aspectos primordiais para o professor/educador desenvolver é o que a Constituição Federal descreve como o preparo para o exercício da cidadania. O professor deve preparar o aluno para esse exercício. Cidadania é um conceito complexo, e há indispensável necessidade de aprofundar seu estudo e investigar o alcance de sua aplicabilidade. O professor deve, a todo momento, questionar seu papel, perguntar a si

\footnotetext{
${ }^{12}$ DEMO, Pedro. Pesquisa e construção do conhecimento, p. 22.

${ }^{13}$ Idem, p. 27. 
mesmo: será que estou cumprindo a contento minha missão de educador, será que estou desenvolvendo plenamente minhas possibilidades? Se ele estiver refletindo sobre suas experiências práticas, apresentando, como professor, as vivências do advogado, temos a certeza que poderá responder positivamente a seus questionamentos, pois estará dando sua melhor contribuição dentro da sala de aula.

A professora Terezinha Azerêdo Rios, em sua obra Compreender e ensinar: por uma docencia de melhor qualidade, tomou emprestado, com muito engenho, um termo, segundo ela, criado pelo sociólogo Herbert de Souza, o inesquecível Betinho. O termo é: felicidadania.

\begin{abstract}
1. Construir a felicidadania, na ação docente, é reconhecero outro. (...) Reconhecer o outro no aluno é considerá-lo na perspectiva da igualdade na diferença, que é o espaço da justiça e da solidariedade. (...) Partimos da diferença real para chegar à igualdade possível (...). 2. Construir a felicidadania, na ação docente, é tomar como referencia o bem coletivo. (...) Trata-se aqui dos princípios que vão nortear a ação do professor. $\mathrm{O}$ que ensinar? Como ensinar? Para quem ensinar? (...) Por que ensinar? Para que ensinar? Se o que se pretende como finalidade, é formar a cidadania, as respostas serão orientadas por ela. (...) 3. Construir a felicidadania, na ação docente, é envolver-se na elaboração e desenvolvimento de um projeto coletivo de trabalho. ${ }^{14}$
\end{abstract}

Trabalhar com projetos é uma das formas de metodologia da educação do futuro ${ }^{15}$. Vejamos mais alguns itens dessa construção da felicidadania:

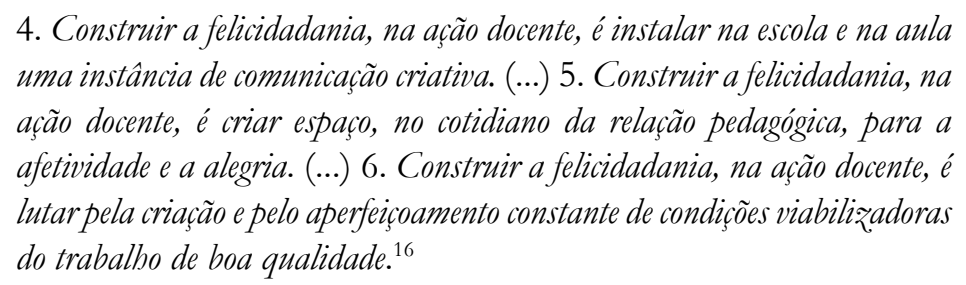

Sabemos ainda que outra questão importante na atividade docente são os temas transversais. Trabalhar com a interdisciplinaridade e com os temas transversais é fundamental para que de fato tenhamos um aprendizado significativo.

\title{
Conclusão
}

Para finalizar sumariamente, gostaríamos de reforçar a idéia da importância da atividade profissional do advogado para o desenvolvimento de sua atividade docente.

\footnotetext{
${ }^{14}$ RIOS, Terezinha Azerêdo. Compreender e ensinar, p. 125-127.

${ }^{15}$ Sobre este assunto há um excelente trabalho do professor Fernando Hernández, Universidade de Barcelona, intitulado Transgressão e mudança na educação: os projetos de trabalho.

${ }^{16}$ Idem, p. $128-132$. 
Sabemos que a tarefa da docência não é fácil, mas é um desafio, é verdadeiramente instigante. Desenvolver constantes e renovados estudos, fazer e ensinar a fazer pesquisa, esses são fatores que vão garantir sucesso tanto na profissão advocatícia quanto na docência universitária.

\section{Referências}

ABBAGNANO, Nicola. Dicionário de filosofia. São Paulo: Martins Fontes, 1999. ALVIM, Márcia Cristina de Souza. Princípio da dignidade da pessoa humana e o direito constitucional do trabalho. 1997. Dissertação (Mestrado em Direito Constitucional) - Pontifícia Universidade Católica, São Paulo, 1997.

CHALLITA, Gabriel. Educação: a solução está no afeto. 4. ed. São Paulo: Gente, 2001.

DEMO, Pedro. Pesquisa e construção do conhecimento. 4. ed. Rio de Janeiro: Tempo Brasileiro, 2000.

HERNÁNDEZ, Fernando. Transgressão e mudança na educação: os projetos de trabalho. Tradução de Jussara Haubert Rodrigues. Porto Alegre: Artmed, 1998.

MONTAIGNE, Michel de. Ensaios. Os pensadores. Tradução de Sérgio Milliet. São Paulo: Abril Cultural, 1972. v. 11.

MORIN, Edgar. A cabeça bem feita. 10. ed. Rio de Janeiro: Bertrand Brasil, 2004.

RIOS, Terezinha Azerêdo. Compreender e ensinar: por uma docência de melhor qualidade. São Paulo: Cortez, 2003.

SILVA, Plácido e. Vocabulário jurídico. São Paulo: Forense, 1973. 